\section{OAK RIDGE NATIONAL LABORATORY}

MARTIN MARIETTA

\section{Additional Verification Problems for HEATING 7.2}

James E. Park
MANAGED BY

MARTIN MABIETTA ENERGY SYSTEMS, INC.

FOR THE UNITED STATES

DEPARTMENT OF ENERGY

\section{RECEIVED}

JUN 161995

O S T I OISTAIBUTION OF THIS DOCUMENT IS UNLIMTEE 
This report has been reproduced directly from the best available copy.

Available to DOE and DOE contractors from the Office of Scientific and Technical Information, P.O. Box 62, Oak Ridge, TN 37831; prices available from (615) 576-8401, FTS 626-8401.

Available to the public from the National Technical Information Service, U.S. Department of Commerce, 5285 Port Royal Rd., Springfield, VA 22161.

This report was prepared as an account of work sponsored by an agency of the United States Government. Neither the United States Government nor any agency thereof, nor any of their employees, makes any warranty, express or implied, or assumes any legal liability or responsibility for the accuracy, completeness, or usefulness of any information, apparatus, product, or process disclosed, or represents that its use would not infringe privately owned rights. Reference herein to any specific commercial product, process, or service by trade name, trademark, manufacturer, or otherwise, does not necessarily constitute or imply its endorsement, recommendation, or favoring by the United States Government or any agency thereof. The views and opinions of authors expressed herein do not necessarily state or reflect those of the United States Government or any agency thereof. 


\section{DISCLAIMER}

\section{Portions of this document may be illegible in electronic image products. Images are produced from the best available original document.}


ORNL/M-4316

Computational Physics and Engineering Division

\title{
ADDITIONAL VERIFICATION PROBLEMS FOR HEATING 7.2
}

\author{
James E. Park
}

Date Published - June 1995

Prepared by the OAK RIDGE NATIONAL LABORATORY

Oak Ridge, Tennessee 37831 managed by

LOCKHEED MARTIN ENERGY SYSTEMS, INC.

$$
\text { for the }
$$

U. S. DEPARTMENT OF ENERGY

under Contract No. DE-AC05-84OR21400

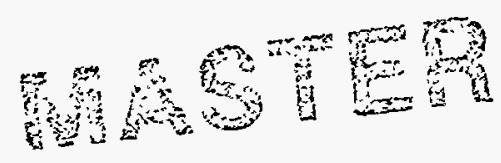




\title{
ADDITIONAL VERIFICATION PROBLEMS FOR HEATING 7.2
}

\begin{abstract}
First estimates of heat transfer coefficients from the quenches at Torrington and IITRI were presented on December 1, 1994, at NCMS. Some of the calculated values were negative. Several suggestions have been made as to the cause of this clearly physically unrealistic result. In this first portion of a systematic investigation of the problem, the thermal analysis code HEATING 7.2 is used to solve two possibly relevant demonstration problems.
\end{abstract}

\section{INTRODUCTION}

\section{Problem}

During the summer of 1994, G. M. Ludtka and W. H. Elliott visited Torrington's facility in North Carolina and the IITRI facility near Chicago. The purpose was to measure temperatures on the surface of gears and nontoothed blanks during quenching. The gears and blanks were representative of those designed for the Saturn automobile. At IITRI, the gears and blanks were quenched in oil using a batch process. At Torrington, the gears were quenched individually into a salt-filled tank intended for large parts. At both facilities, some of the quenches were videotaped.

The data from one gear blank (blank No. 13) quenched at Torrington are the focus of the problem addressed by this report. After a suitable digital smoothing algorithm was developed, the smoothed data were used as initial and boundary conditions to calculate the surface heat flux experienced during the quench.

The calculated heat fluxes were negative at some of the thermocouples for portions of the quench. Negative values are clearly not a physical possibility. Since the surface heat fluxes are negative, this analysis will concentrate on the calculation of those fluxes; the translation to surface heat transfer coefficients is straightforward. If the heat flux problem is identified and corrected, the heat transfer coefficients will also be correct.

\section{Suggested Causes}

The following causes have been suggested for this problem:

1. Analysis code errors - the heat transfer code being used for the data reduction has an error.

2. Data biases - the data contain measurement errors, or the data are being processed incorrectly.

3. Insufficient data - eight thermocouple readings on the surface of a [two-dimensional (2-D)] shape are not sufficient to define the surface temperature.

4. Inadequate thermophysical modeling - the properties are too simplified.

In this memo, I will examine the first of these possible reasons for the negative surface heat flux. 


\section{DISCUSSION}

\section{HEATING 7.2}

The analysis code used for this work is HEATING 7.2, ${ }^{1}$ developed at ORNL. In 1986, a set of verification problems was collected and documented. ${ }^{2}$ Since then, major changes and upgrades to the HEATING system have been tested against those problems. Twenty-three problems were run. They include transient and steady-state configurations in Cartesian, cylindrical, and spherical coordinate systems. Problems with one, two and three space dimensions are included. In particular, three problems in the suite are one-dimensional (1-D) transient problems with an abrupt discontinuity in one surface boundary condition. These problems all possess analytic solutions. Copies of Ref. 1 and 2 will be provided on request to the writer.

An additional test problem with abrupt boundary conditions has been run. Also, the data from two of the test thermocouples have been used to check HEATING 7.2 for self-consistency. In this check, the temperatures were used as initial and boundary conditions to calculate surface heat flux histories for a 1-D analog of the 2-D gear blank. In a separate calculation, the surface heat flux history from the first problem was used as boundary conditions for the second problem. The results of these studies follow.

For this demonstration, thermal properties representative of the Swedish steel SIS 2511 were used:

$$
\mathrm{k}=0.035 \mathrm{~W} / \mathrm{mm}-{ }^{\circ} \mathrm{C}, \rho=7.9 \times 10^{-6} \mathrm{~kg} / \mathrm{mm}^{3}, \mathrm{c}=600.0 \mathrm{~J} / \mathrm{kg}-{ }^{\circ} \mathrm{C} \text {. }
$$

Dependence of these properties on temperature and on the metallurgical composition was ignored. Similarly, latent heat release due to metallurgical phase changes was neglected.

\section{Test Problems}

Instantaneous Contact of Two Solids at Different Temperatures. This test problem was suggested by Chenoweth. ${ }^{3}$ Two semi-infinite solids initially at different temperatures are suddenly brought into intimate contact. The temperature and heat flux at the interface between the solids can be calculated analytically. The problem can also be simulated numerically.

${ }^{1}$ Childs, K. W., HEATING 7.2 User's Manual, ORNL/TM-12262, Martin Marietta Energy Systems, Inc., Oak Ridge Nat. Lab., Oak Ridge, Tenn., February 1993.

${ }^{2}$ Bryan, C. B., K. W. Childs, and G. E. Giles, HEATING6 Verification, K/CSD/TM-61, Martin Marietta Energy Systems, Inc., Oak Ridge, Tenn., December 1986.

${ }^{3}$ Chenoweth, Don, Visual Aids Used at Meeting of the Heat Transfer Boundary Condition Subgroup, NCMS, Ann Arbor, Mich., April 6, 1995. 
For the test problem, the solid for $\mathrm{x}<0$ has been assigned the thermophysical properties of Partherm 290. The values used are:

$$
\rho=1.653 \times 10^{-6} \mathrm{~kg} / \mathrm{mm}^{3}, \mathrm{k}=5.711 \times 10^{-4} \mathrm{~W} / \mathrm{mm}-{ }^{\circ} \mathrm{C}, \mathrm{c}=1.547 \times 10^{3} \mathrm{~J} / \mathrm{kg}-{ }^{\circ} \mathrm{C} \text {. }
$$

The initial temperature of that material is taken to be $T_{q}=1.0$. The solid for $x>0$ has been assigned properties typical of SIS 2511, given above, and the initial temperature $T_{2}=2.0$. According to Chenoweth, the solution for the interface temperature $T_{\mathfrak{l}}$ is constant for $t>0$ and is given by

$$
T_{I}=T_{q} \frac{\frac{T_{s}}{T_{q}}+R}{I+R}=1.914
$$

where

$$
R^{2}=\frac{(\rho c k)_{q}}{(\rho c k)_{\alpha}}=0.09382, \quad R=0.0 .00880
$$

The interface heat flux is given by

$$
q_{I}=\left(T_{I}-T_{q}\right)\left[\frac{(\rho c k)_{q}}{\pi t}\right]^{0.5} .
$$

The heat flux and temperature at the material interface is shown in Fig. 1; both the numerical and analytic solutions are indicated. At the scale shown the solutions are coincident. In Fig. 2 the solutions are shown for times near $t=0$.

A mesh resolution study is summarized in Figs. 3 and 4. In Fig. 3, the temperature solutions at small times are indicated for four mesh spacings. In Fig. 4, the interface temperatures at $t=0.0100$ $\mathrm{s}$ and $\mathrm{t}=0.0049 \mathrm{~s}$ are shown as functions of the mesh spacing. The point shown for zero mesh spacing is the theoretical value from Eq. (1).

Figures 5 and 6 show the behavior of temperature vs distance at various times. In Fig. 5 , the calculated temperature is shown over the entire span of the problem $(-28.35$ to $28.35 \mathrm{~mm})$. Figure 6 indicates details in the vicinity of the interface $( \pm 0.10 \mathrm{~mm})$. The analytic solutions are dashed lines connecting symbols. Except at the earliest times, the numerical and theoretical solutions coincide. 


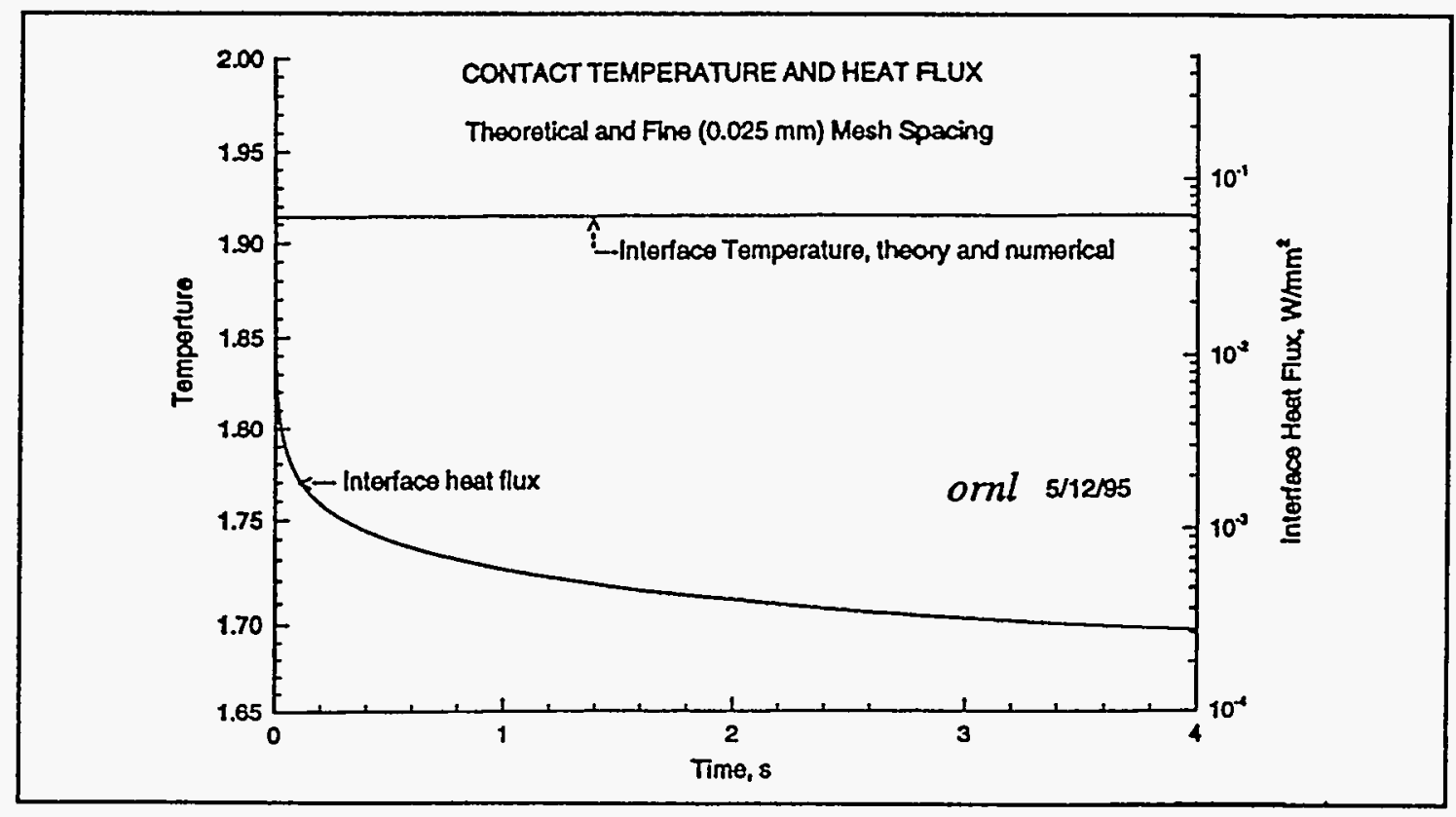

Fig. 1. Numerical and theoretical solutions for contact temperature and heat flux.

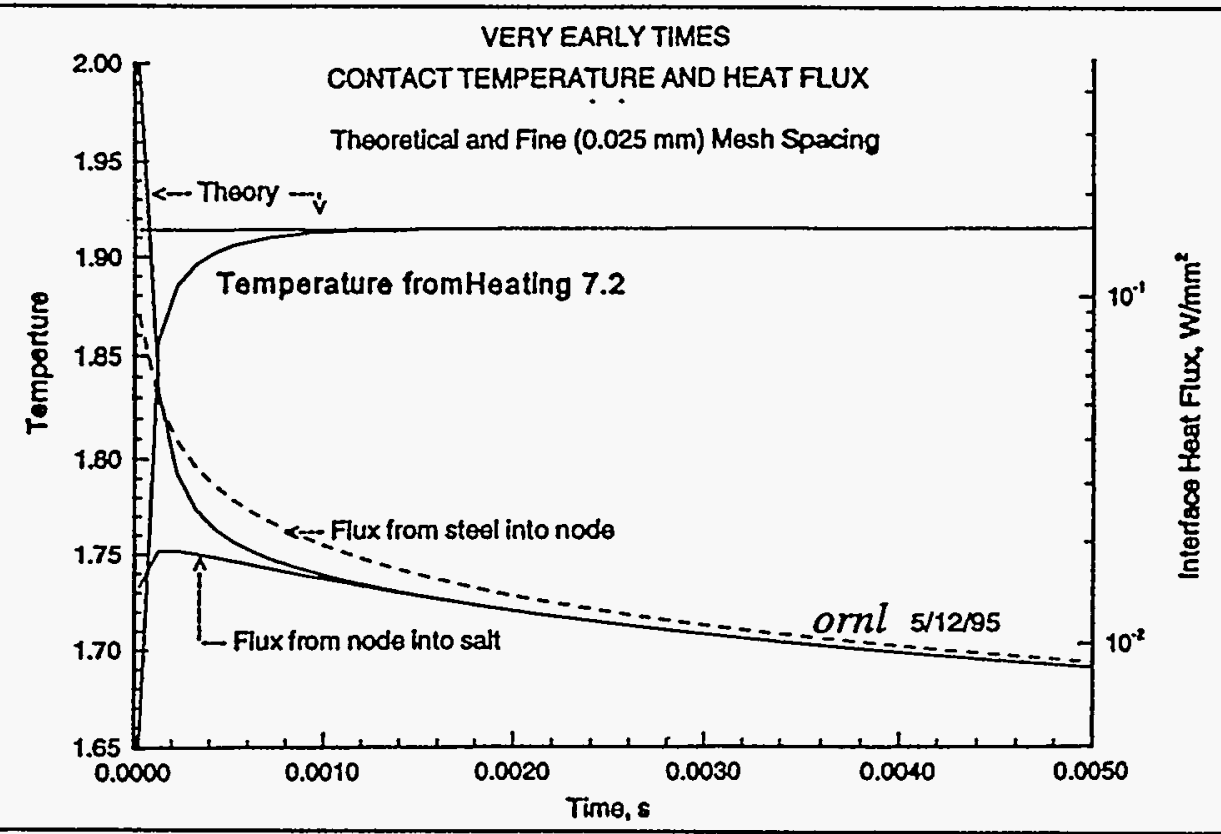

Fig. 2. Contact temperature and contact heat flux at early times. 


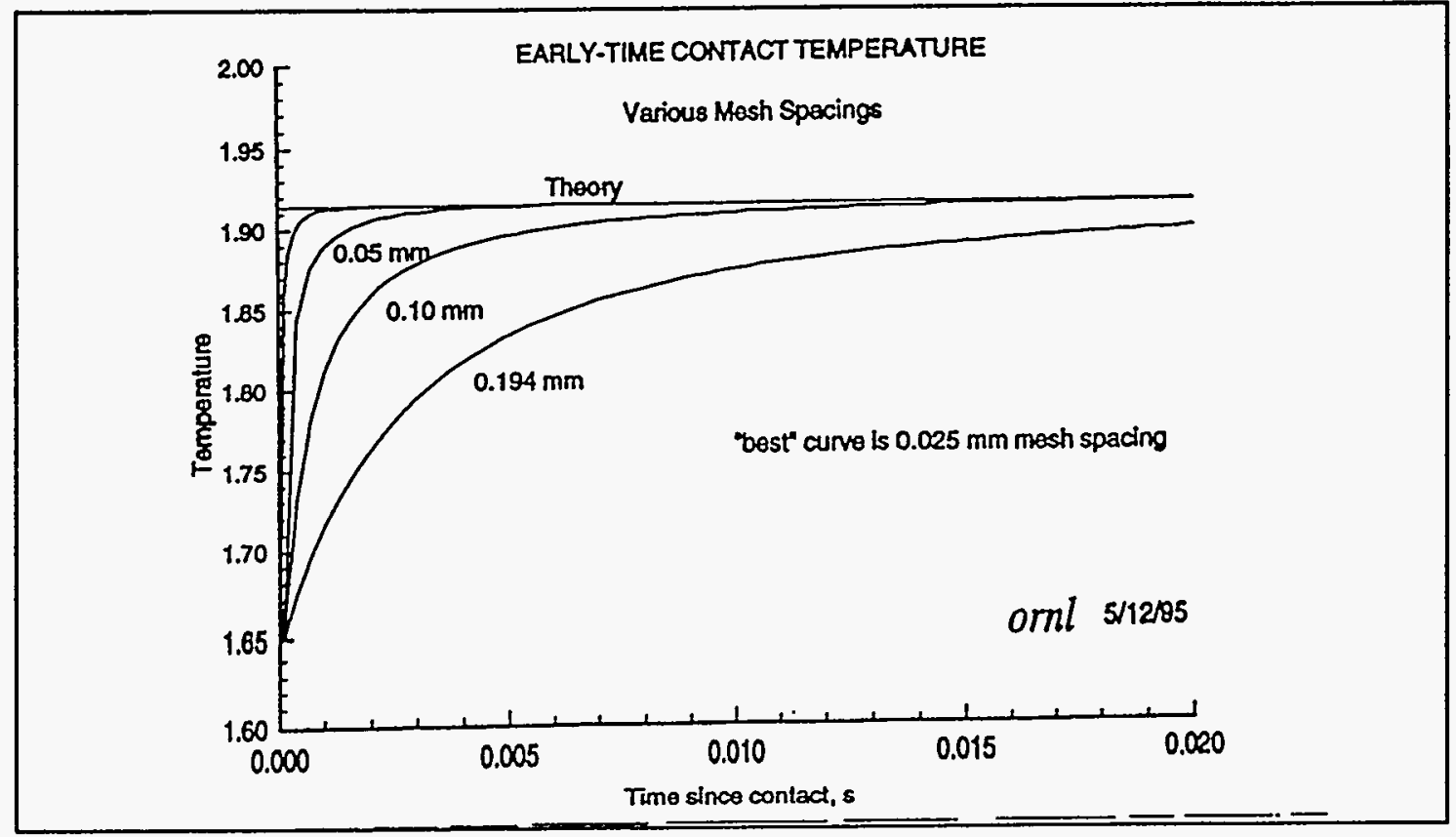

Fig. 3. Contact temperature at early times for several mesh spacings.

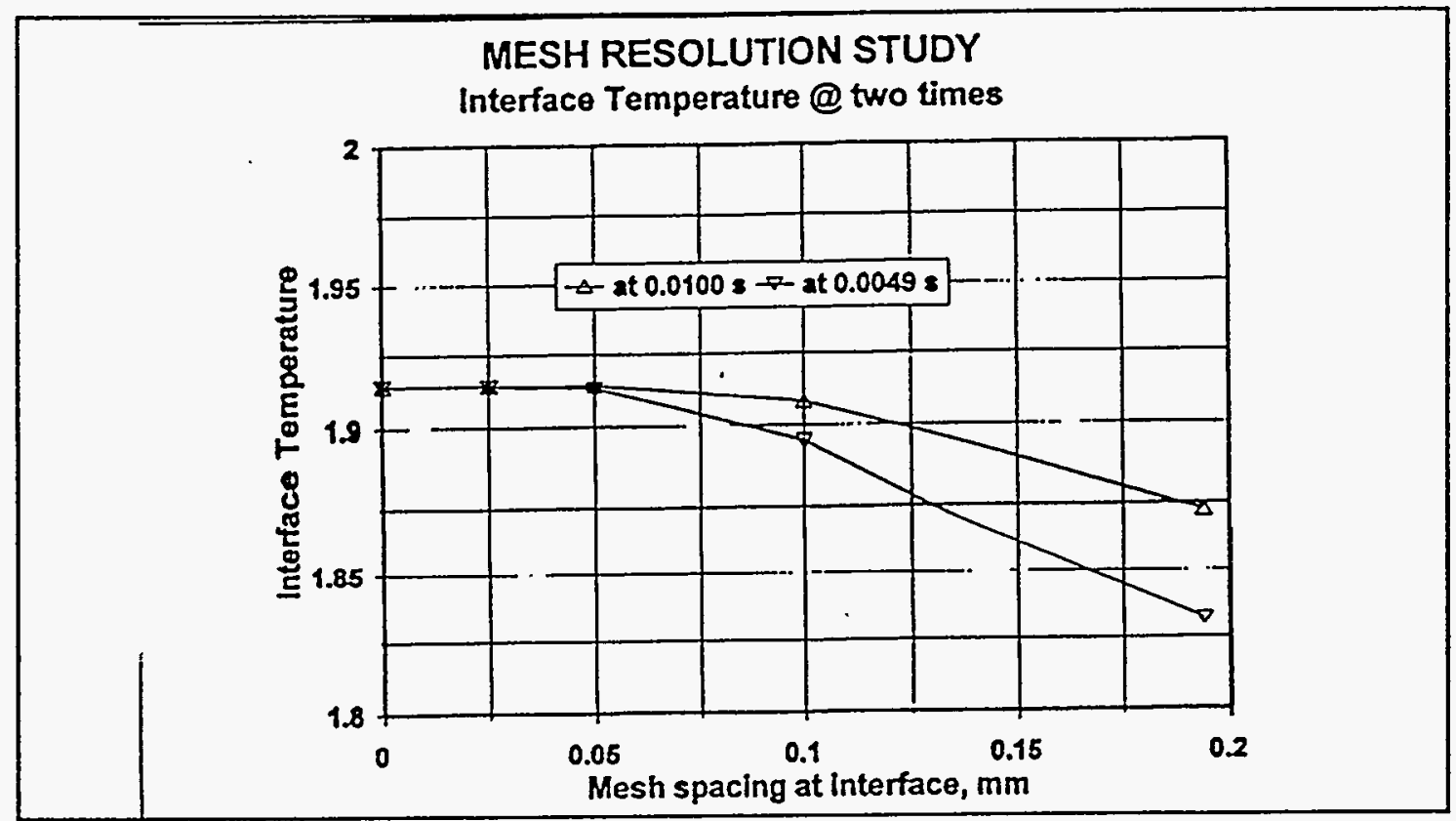

Fig. 4. Contact temperature at 0.01 and $0.0049 \mathrm{~s}$ for several mesh spacings. 


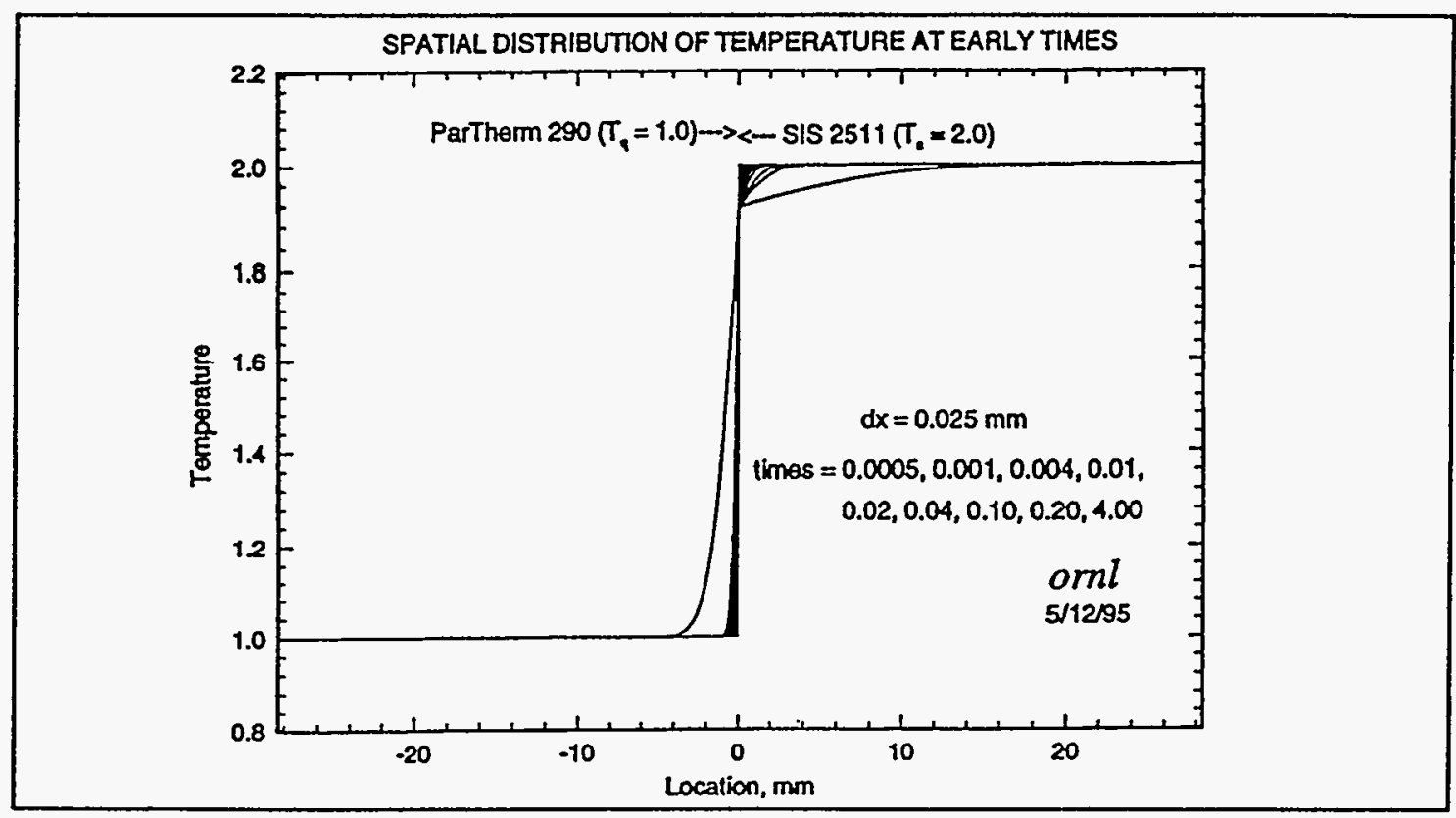

Fig. 5. Spatial temperature distribution at several times.

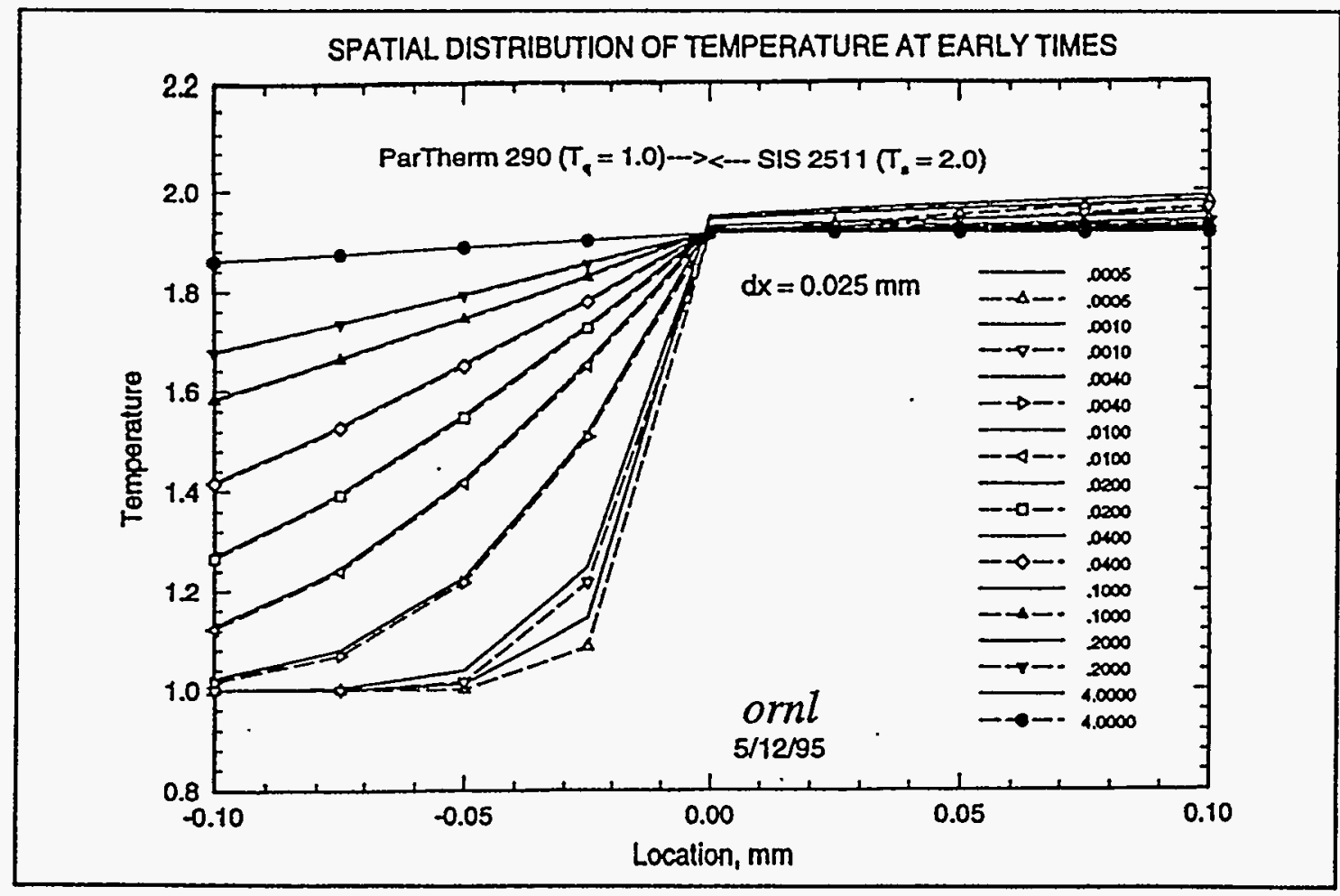

Fig. 6. Detailed temperature distribution near the interface between the materials. 
One-dimensional analog to blank quenched in salt. The final problem is a 1-D simplification of the 2-D shape, which is shown in Fig. 7. The thermocouples numbered 3 and 7 are located on opposite surfaces of the blank, midway between the top and bottom flanks. Data recorded for thermocouples 3 and 7 during the experiments described above were used as boundary conditions to calculate the transient temperatures and surface heat flux during a simulation of the quench. The HEATING 7.2 code was used to calculate the steady-state initial temperature distribution through the blank.

The temperature history for thermocouple 3 and the surface heat flux resulting from that input is shown in Fig. 8. For the second portion of the problem, the surface heat flux obtained from the first problem is used as a boundary condition. The temperature

THERMOCOUPLE LOCATION on

GEAR BLANK DURING QUENCHING

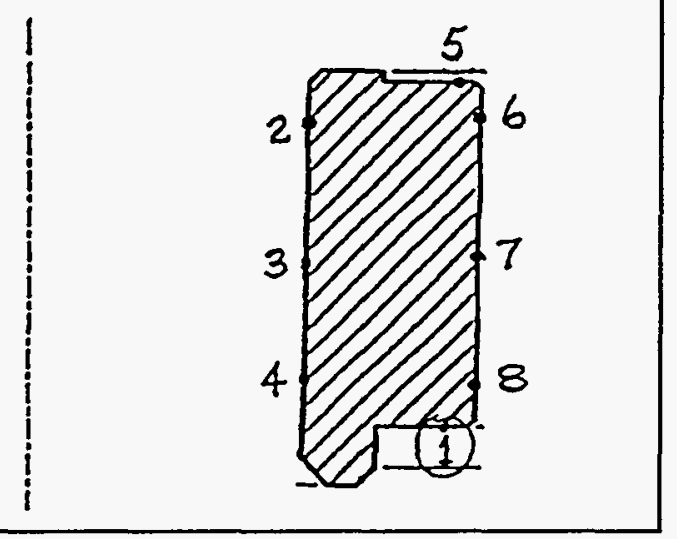

Fig. 7. Thermocouple location on blank 13. calculated on the inner surface during the second problem (thermocouple 3) is shown in Fig. 9. Visually, the temperature curves shown in Figs. 8 and 9 are identical. The small difference between the two is also plotted in Fig. 9. For most of the quench, the error is constant at $-0.00543{ }^{\circ} \mathrm{C}$. The maximum value, $+0.00036^{\circ} \mathrm{C}$, occurs at $\mathrm{t}=0$. The results for temperatures at thermocouple 7 (not shown) were similar.

\section{CONCLUSIONS}

The HEATING 7.2 thermal analysis code has been checked using a problem possessing an analytic solution and a problem derived by simplifying the model and data actually obtained during quenches in an industrial setting.

The closed-form analytic solution is not defined at $t=0$. HEATING 7.2 (and many numerical heat transfer codes) reacts to abrupt changes in initial or boundary conditions by smoothing them out. For the problem solved here, the numerical solution shows some error at small times; the error shrinks consistently as the mesh spacing near the material discontinuity is reduced. There is no evidence of pathological behavior in the results obtained using HEATING 7.2.

The consistency check, consisting of two complementary problems, yielded quite satisfactory results. Temperatures from the two calculations show a maximum error of less than $6 \times 10^{-3}{ }^{\circ} \mathrm{C}$. 


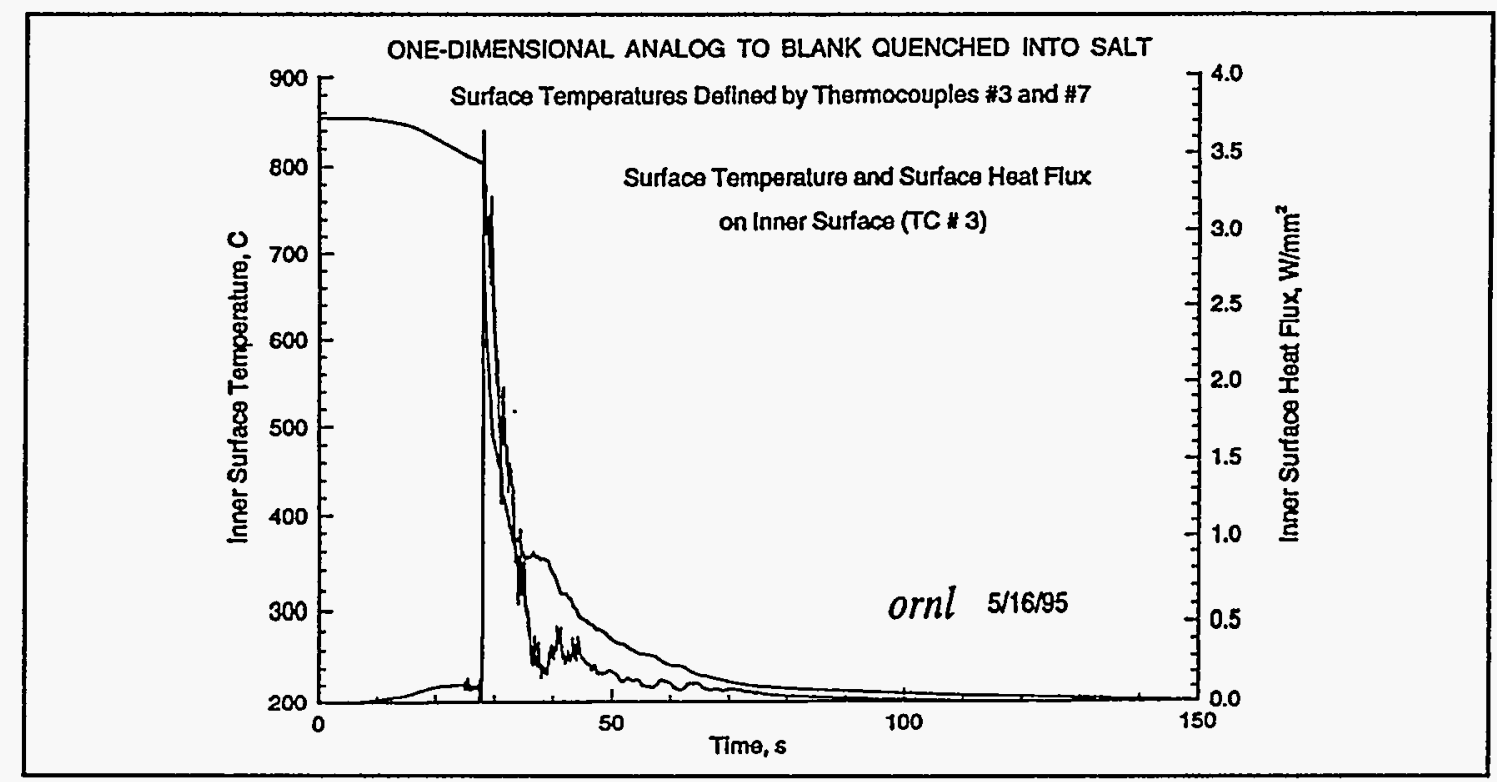

Fig. 8. Input temperatures and resulting surface heat flux curves for 1-D analog of blank 13 .

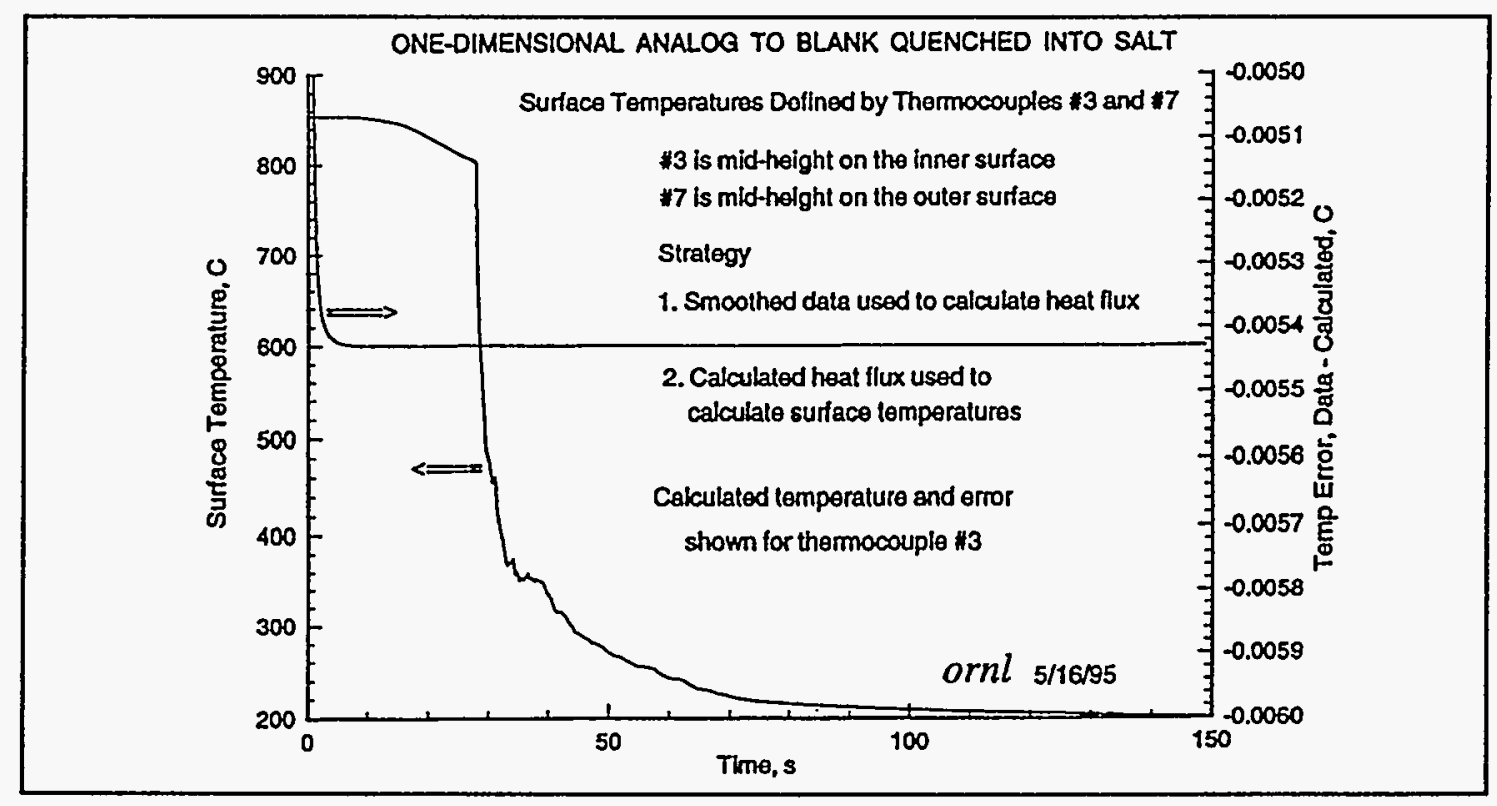

Fig. 9. Calculated temperatures and errors (relative to input temperatures) for consistency test of HEATING 7.2. 
Altogether, the results of this study show no anomalous behavior in the thermal analysis code HEATING 7.2.

\section{ACKNOWLEDGEMENTS}

The writer wishes to recognize the assistance of K. W. Childs, who developed the user routines to impose the boundary conditions needed for some of these problems. C. H. Shappert performed the technical editing. 


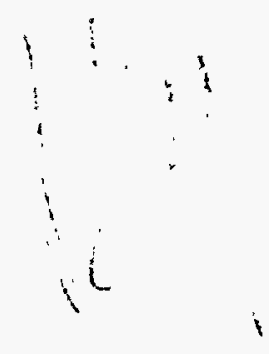




\section{INTERNAL DISTRIBUTION}

1. K. W. Childs

2. W. H. Elliott

3. Gerard M. Ludtka

4. J. E. Park

5. M. A. Kuliasha

6-8. C. H. Shappert

9. Central Research Library
10. ORNL Y-12 Technical Library Document Reference Section

11. Laboratory Records Department

12. Laboratory Records Department, RC

13. ORNL Patent Office

\section{EXTERNAL DISTRIBUTION}

14. Office of Deputy Assistant Manager for Energy Research and Development, Department of Energy, Oak Ridge Operations, P. O. Box 2008, Oak Ridge, TN, 37831-6269

15-16. Office of Scientific and Technical Information, U. S. Department of Energy, P. O. Box 62, Oak Ridge, TN 37831

17. Tracy Pattok, National Center for Manufacturing Sciences, 3025 Boardwalk, Ann Arbor, MI 48108 